\begin{tabular}{|c|c|}
\hline \multirow{3}{*}{ 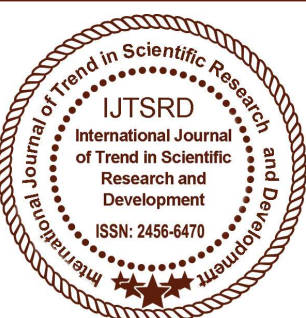 } & $\begin{array}{l}\text { International Journal of Trend in Scientific } \\
\text { Research and Development (IJTSRD) }\end{array}$ \\
\hline & International Open Access Journal \\
\hline & ISSN No: 2456 - 6470 | www.ijtsrd.com | Volume - 2 | Issue - 5 \\
\hline
\end{tabular}

\title{
Difficulties Small Business Face Due to Marekt Conditions
}

\author{
Arihant Agrawal \\ B.B.A., L.L.B. (Hons), Indore Institute of Law, \\ Indore, Madhya Pradesh, India
}

\begin{abstract}
Micro, Small and Medium Enterprise (MSME) sector has emerged as a highly vibrant and dynamic sector of the Indian economy over the last five decades. MSMEs not only play crucial role in providing large employment opportunities at comparatively lower capital cost than large industries but also help in industrialization of rural \& backward areas, thereby, reducing regional imbalances, assuring more equitable distribution of national income and wealth. MSMEs are complementary to large industries as ancillary units and this sector contributes enormously to the socio-economic development of the country. The researcher has tried to find out the possible difficulties that small enterprises face in the market. The reasons behind the failure of maximum small enterprises in Indian market. The market policies which effect such businesses and also the steps taken by the government to relief the small market enterprises. Some of the important policies have been discussed in the paper introduced by the government or which already exists. The researcher has tried to give solutions to solve such problems incurred by the SME's. The researcher has tried to find the existing governmental policies which will ease in doing business and also provide suggestions to solve the problems being faced by such business organisations.
\end{abstract}

\section{INTRODUCTION}

Definitions of Micro, Small \& Medium Enterprises: In accordance with the provision of Micro, Small and Medium Enterprises Development (MSMED) Act, 2006 the Micro, Small \& Medium Enterprises (MSME) are classified in two classes:

1- Manufacturing Enterprises- The enterprises engaged in the manufacture or production of goods pertaining to any industry specified in the first schedule to the industries (Development and regulation) Act, 1951) or employing plant and machinery in the process of value addition to the final product having a distinct name or character or use. The Manufacturing Enterprise are defined in terms of investment in Plant \& Machinery.

2- Service Enterprise- The enterprises engaged in providing or rendering of services and are defined in terms of investment in equipment.

\begin{tabular}{|l|l|}
\hline \multicolumn{2}{|c|}{ Manufacturing Sector } \\
\hline Enterprises & $\begin{array}{l}\text { Investment in plant \& } \\
\text { machinery }\end{array}$ \\
\hline $\begin{array}{l}\text { Micro Enterprises } \\
\text { Ch and }\end{array}$ & $\begin{array}{l}\text { Does not exceed twenty-five } \\
\text { lakh rupees }\end{array}$ \\
\hline Small Enterprises & $\begin{array}{l}\text { More than twenty-five lakh } \\
\text { rupees but does not exceed } \\
\text { five crore rupees }\end{array}$ \\
\hline Medium Enterprises & $\begin{array}{l}\text { More than five crore rupees } \\
\text { but does not exceed ten crore } \\
\text { rupees }\end{array}$ \\
\hline Service Sector \\
\hline Micro Enterprises & $\begin{array}{l}\text { Investment } \\
\text { Equipment }\end{array}$ \\
\hline Small Enterprises & $\begin{array}{l}\text { Does not exceed ten lakh } \\
\text { rupees }\end{array}$ \\
\hline Medium Enterprises & $\begin{array}{l}\text { More than ten lakh } \\
\text { rupees but does not } \\
\text { exceed two crore rupees } \\
\text { More than two crore } \\
\text { rupees but does not } \\
\text { exceed five crore rupees }\end{array}$ \\
\hline
\end{tabular}

\footnotetext{
${ }^{1}$ http://dcmsme.gov.in/ssiindia/defination_msme.htm
} 
Only in India the categorisation of different industries into Micro, Small, Medium and Large is done on the basis of the capital (excluding investments in land and building) thrown into the business where as in Europe region and rest of the world the categorisation is done on the basis of human input implied or the number of employees employed in that particular organisation with shareholder funds and sale of products. For example- if less than 50 employees work in an organisation then the organisation is kept under micro level organisation or micro level business enterprise.

Micro, Small and Medium Enterprises (MSME) sector has emerged as a highly vibrant and dynamic sector of the Indian economy over the last five decades. MSMEs not only play crucial role in providing large employment opportunities at comparatively lower capital cost than large industries but also help in industrialization of rural \& backward areas, thereby, reducing regional imbalances, assuring more equitable distribution of national income and wealth. MSMEs are complementary to large industries as ancillary units and this sector contributes enormously to the socio-economic development of the country.

The Sector consisting of 36 million units, as of today, provides employment to over 80 million persons. The Sector through more than 6,000 products contributes about $8 \%$ to GDP besides $45 \%$ to the total manufacturing output and $40 \%$ to the exports from the country. The MSME sector has the potential to spread industrial growth across the country and can be a major partner in the process of inclusive growth.

Flourishing amidst a challenging environment, the Small and Medium Enterprises (SMEs) of India experienced several highs and lows in the past few years. With the Indian economy expected to emerge as one of the leading economies in the world and likely to become $\$ 5$ trillion economy by 2025 , major impetus is being given to strengthen the backbone of our economy- the SME sector. Comprehending the significance of the SME sector vis-à-vis lending numbers to the job market, contribution to GDP and fostering entrepreneurship and innovation. ${ }^{2}$

\footnotetext{
${ }^{2}$ https://economictimes.indiatimes.com/small-biz/smesector/indian-sme-trends-the-year-gone-by-and2017/articleshow/56254240.cms
}

Small Scale Industries do not enjoy much of the advantages enjoyed by large scale enterprises because of their nature and size. ${ }^{3}$ They do not enjoy their giving's to the economy in return as they are not able to realise their full potential despite significant contribution to the Indian Economy. Many of the Small-Scale Industries are sick and face many problems in functioning.

\section{Various Problems faced by SME's are-}

\section{1- Financial problems}

The most important thing required for a business is its capital and financing issues are the primary problems faced by every industry or business irrespective of its size! Many small -scale industries face the problem of scarcity of funds. They are not able to access the domestic capital market to raise resources. They are also not able to tap foreign markets by issuing ADR's (American Depository Receipts) GDR's (Global Depository Receipts) etc because of their small capital base. Banks and financial institutions require various procedures and formalities to be completed. Even after a long delay, the funds allocated are inadequate. Bank credit to small scale sector has always been an issue. Small Scale Industries are not able to get funds immediately for their needs. They have to depend on private money lenders who charge high interest. Finance, as a whole, both long and short term, accounts for as large as $43 \%$ of the sector's sickness. ${ }^{4}$ Some major problems that approximately $80 \%$ MSME Entrepreneurs face on a day-to-day basis while trying to obtain credit assistance for their business operations:

i. Complex collaterals required to obtain term loans

ii. High transaction costs in imports/exports

iii. Private Equity Funding is difficult to obtain

iv. Banks offer high rates for term loans

v. Private equity (PE) dilutes control in the company

vi. Cumbersome procedures and delay in fund disbursement

\section{2- Problems related to Raw materials-}

SME's generally depend on local sources of raw material. They have to purchase raw material in small quantities and often on credit. Apparently, they cannot

\footnotetext{
${ }^{3}$ https://accountlearning.com/what-are-the-problems-faced-bysmall-scale-industries-in-india/

${ }^{4}$ http://www.ijstm.com/images/short_pdf/1457509568_729H.pdf
} 
compete with large-scale industries in the procurement of raw material. In many cases the raw material is an imported item. Quite often, small industries have to pay a higher price for inputs and suffer uncertainty in their procurement. Nonavailability of quality raw materials like dyes and yarn (especially for handlooms and power looms ), vital inputs like power (for power looms, handicrafts, other industrial SMEs) and proper packaging facilities continue to be major bottlenecks. Lack of credit combined with inadequate raw material often pushes weavers, artisans, entrepreneurs into the clutches of loan sharks and middlemen. Though the National Small Industries Corporation are providing some raw materials, their efforts are not in consonance with the requirements. The capacity of SMEs to buy raw materials is limited and at times when the material is needed, it is not readily available. Considering their financial constraints and the need for minimizing their inventory costs, SMEs are forced to buy small amounts of needed raw-materials as and when the actual need arises. Their capacity to withstand the consequences of fluctuations in the prices of raw materials is also low.

\section{3- Marketing related issues-}

Small Scale Industries lack market knowledge with regard to competitors, consumer preferences, market trends. Since their production volume is small and cannot meet demand for large quantities their market is very restricted. Now with the process of liberalization and globalization they are facing competition from local industries as well as foreign competitors who sell better quality products at lower prices. ${ }^{5}$ The need for enterprises to increase market coverage, improve operational efficiencies and enhance customer engagement is imperative. However, this requires readiness on two accounts the company and government regulation and policies including SME special programs, initiatives and funds.

\section{4- Technological Constraints-}

Small scale entrepreneurs are not fully exposed to the latest technology. ${ }^{6}$ Moreover, they lack requisite resources to update or modernise their plant and machinery Due to obsolete methods of production, they are confronted with the problems of less production in inferior quality and that too at higher

\footnotetext{
${ }^{5}$ Supra 5

${ }^{6}$ http://www.yourarticlelibrary.com/industries/10-majorproblems-faced-by-the-small-scale-industries-of-india/23457
}

cost. They are in no position to compete with their better equipped rivals operating modem large scale units. MSMEs have a unique problem to solve - while they are required to adhere to global standards and ensure compliance to regulations, they mostly have limited understanding (and budgets) for technology. MSMEs expect the Government to take necessary steps to provide modern technology at cheaper and subsidized cost, enable ecosystem to facilitate technology transfer, create a platform for technology providers and technology seekers.

\section{5- Multiplicity of Labour laws-}

One of the merits of Small Scale Industries are that they are labour intensive and can provide employment to a large number of people. But the multiplicity of labour laws, need to maintain several records (PF, ESI, Muster Rolls etc), fines and penalties for minor violations etc place Small Scale Industries at a great disadvantage. Labour laws provisions such as standardized wages, social security, and job safety ensure that the workforce is protected and delivers its highest output. The MSMEs require government-led initiatives and schemes for competency and skill development to ensure SMEs don't have under-skilled workers.

\section{6- Lack of Skilled Human Resource-}

Non-availability of skilled workforce and better managerial/entrepreneurial expertise at affordable cost near the location of enterprises is another such big challenge for the MSMEs in our country. Lack of managerial competence, absence of proper training on resource planning and capital management etc. hinders the growth of enterprises.

\section{7- Globalisation -}

Due to liberalisation and opening up of the economy, SMEs are facing stiff competition from imports and need technological upgradation to produce better quality products at cheap rates. Many segments of SMEs especially the traditional sectors, find it difficult to compete against aggressive marketing by the big domestic and multinational players. Street vendors, petty traders, handloom and power loom weavers, home based food processing units, Khadi institutions, Zari workers and rural artisans, many of whom have even lost livelihoods and places of work due to developmental works, are the worst affected. There is a need to evolve a constructive response to this situation. 


\section{8- Infrastructure-}

Deficiencies in the infrastructure and poor support facilities marked by inadequate access to basic facilities like water, power supply, $\mathrm{road} / \mathrm{rail}$ connectivity etc. adversely affect this sector and contribute to enhance their operational cost by rendering the MSMEs less competitive in the challenging market situations. Inadequate and inappropriate transportation and communication network will make the working of various units all the more difficult. All these factors are going to adversely affect the quantity, quality and production schedule of the enterprises operating in these areas. Thus, their operations will become uneconomical and unviable.

\section{9- Under Utilisation of Capacity-}

Most of the small-scale units are working below full potentials or there is gross underutilization of capacities. Large scale units are working for 24 hours a day i.e. in three shifts of 8 hours each and are thus making best possible use of their machinery and equipment. On the other hand, small scale units are making only 40 to 50 percent use of their installed capacities. ${ }^{7}$ Various reasons attributed to this gross under- utilisation of capacities are problems of finance, raw material, power and underdeveloped markets for their products.

\section{0- Lack of Awareness-}

The government has set up many organizations to support and provide assistance to Small Scale Industries. But, many of the entrepreneurs running Small Scale Industries are not aware of the various support services.

\section{Steps taken by the Government-}

On 9 May 2007, subsequent to an amendment of the Government of India (Allocation of Business) Rules, 1961, erstwhile Ministry of Small Scale Industries and the Ministry of Agro and Rural Industries were merged to form the Ministry of Micro, Small and Medium Enterprises (M/o MSME). This Ministry now designs policies and promotes/ facilitates programs, projects and schemes and monitors their implementation with a view to assisting MSMEs and help them to scale up. The primary responsibility of promotion and development of MSMEs is of the State Governments. However, the Government of India,

\footnotetext{
${ }^{7} \mathrm{https}$ //www.indiainfoline.com/article/news-topstory/problems-faced-by-sme-in-india-116011800359_1.html
}

supplements the efforts of the State Governments through various initiatives. The role of the M/o MSME and its organisations is to assist the States in their efforts to encourage entrepreneurship, employment and livelihood opportunities and enhance the competitiveness of MSMEs in the changed economic scenario. ${ }^{8}$

1- Performance and Credit Rating Scheme- ${ }^{9}$

The scheme is being implemented through National Small Industries Corporation (NSIC) Limited. The main objective of the scheme is to provide a trusted third party opinion on the capabilities of the MSEs so as to create awareness amongst them about the strengths and weakness of their existing operations. Rating under the scheme is being carried out through empanelled rating agencies i.e. CRISIL, CARE, ONICRA, SMERA, ICRA and Brickwork India Ratings. Under this Scheme, rating fee payable by the micro \& small enterprises is subsidized for the first year only and that is subject to maximum of $75 \%$ of the fee or Rs. 40000/-, whichever is less.

2- Marketing Assistance Scheme-

The scheme is being implemented through National Small Industries Corporation (NSIC) Limited. The main objectives of the scheme is to enhance the marketing competitiveness of MSMEs; to provide them a platform for interaction with the individual/institutional buyers; to update them with prevalent market scenario and to provide them a form for redressing their problems. MSMEs are supported under the Scheme for capturing the new market opportunities through organising/ participating in various domestic \& international exhibitions/ trade fairs, Buyer-Seller meets intensive campaigns and other marketing events.

3- International Cooperation (IC) Scheme-

Technology infusion and/or upgradation of Indian micro, small and medium enterprises (MSMEs), their modernisation and promotion of their exports are the principal objectives of assistance under the Scheme. The Scheme would cover the following activities:(a) Deputation of MSME business delegations to other countries for exploring new areas of technology infusion/upgradation, facilitating joint ventures, improving market of

https://msme.gov.in/sites/default/files/MSME_at_a_GLANCE_2 016_Final.pdf last visited on 17/07/2018 at 19:00

9 ibid 
MSMEs product foreign collaborations, etc; (b) Participation by Indian MSMEs in international exhibitions, trade fairs and buyer seller meets in foreign countries as well as in India, in which there is international participation; (c) Holding international conferences and seminars on topics and themes of interest to the MSME. IC Scheme provides financial assistance towards the airfare and space rent of entrepreneurs.

4- Assistance to Training Institutions Scheme-

The Scheme envisages financial assistance for establishment of new institutions (EDIs), strengthening the infrastructure of the existing EDIs and for supporting entrepreneurship and skill development activities. The assistance shall be provided to these training institutions in the form of capital grant for creation/strengthening of infrastructure and programme support for conducting entrepreneurship development and skill development programmes. Maximum assistance for creation or strengthening of infrastructure will be Rs. 150 lakhs on matching basis, not exceeding $50 \%$ of project cost. However, for the North Eastern region (including Sikkim), Andaman \& Nicobar and Lakshadweep, the maximum assistance on matching basis would be Rs. 270 lakhs or $90 \%$ of project cost, whichever is less.

5- MSME Talent/ Job Melas-

A new initiative was taken up under the ATI scheme in making available skilled persons for the MSMEs in the country. As part of this, ni-msme conducted MSME Talent/ Job Melas at different places across the country bringing employers and the skilled persons to a common platform. These melas are directly providing employment to the trained youth and indirectly encouraging the youth to participate in ESDPs, while also enhancing the success rate of the programmes.

6- Schemes for Khadi \& Village Industries Sector-

Prime Minister's Employment Generation Programme (PMEGP) is a credit linked subsidy scheme of the Ministry, implemented through KVIC, DICs and State KVI Boards with KVIC as the Nodal Agency at the national level for setting up new self-employment ventures/projects/micro enterprises to generate employment opportunities in rural as well as urban areas of the country. The other objective is to bring together widely dispersed traditional artisans/rural and urban unemployed youth and give them self employment opportunities to the extent possible, at their place so as to help arrest migration of rural youth to urban areas. Any individual, above 18 years of age can avail the benefit of this programme. However, assistance under the Scheme is available only for new projects sanctioned specifically under the PMEGP.

7- Scheme of fund for Regeneration of Traditional Industries (SFURTI)- ${ }^{10}$

With a view to making the traditional industries more productive and competitive and facilitating their sustainable development, the Govt. of India announced setting up of a fund for regeneration of traditional industries. The objective is to organize the traditional industries and artisans into clusters to make them competitive and provide support for their long term sustainability and economy of scale, and provide sustained employment for traditional industry artisans and rural entrepreneurs to enhance marketability of products of such clusters by providing support for new products, design intervention and improved packaging and also the improvement of marketing infrastructure.

8- Organizing International Technology Exhibitions in Foreign Countries by NSIC and participation in International Exhibitions/Trade Fairs:

9- Organizing Domestic Exhibitions and Participation in Exhibitions/ Trade Fairs in India

10-"Techmart" exhibition by NSIC:

11-Support for Co-sponsoring of Exhibitions organized by other organizations/ industry associations/agencies

12- Buyer-Seller Meets organized by NSIC

13-Intensive Campaigns and Marketing Promotion Events

14- Time for registering companies reduced: The government has made the process for registering a company faster by reducing the time taken from almost 10 days in December 2014 to 5 days in December 2015. This year the government plans to further reduce the time taken to 1-2 days.

15- Easier processes for incorporation: To make the process of registering and incorporating companies faster, the government has done away with the requirement of reserving a name, and integrated the processes related to allotment of Director Identification Number (DIN), appointment of directors etc in a single form (INC - 29) for incorporation of a company. 
International Journal of Trend in Scientific Research and Development (IJTSRD) ISSN: 2456-6470

16- Integration of processes through eBiz portal $^{11}$ : The eBiz platform of the Department of Industrial Policy and Promotion (DIPP) integrates several processes across (government) departments to make the process of incorporating a company simpler. One can apply for Permanent Account Number (PAN), Tax Deduction Account Number (TAN), EPFO (Employees' Provident Fund Organization) and ESIC (Employee's State Insurance Corporation) and incorporation of company through the eBiz portal.

17- MUDRA BANK-

Allocation of Rs.20,000 crore for Micro Units Development Refinance Agency (MUDRA) Bank for the SME sector and will enhance facility to boost the growth of small businesses and manufacturing units. It consists of Rs. 1,000 crore for support of start-ups. Mudra bank has been launched on $8^{\text {th }}$ April 2015. It will provide credit up to Rs. 10 lakh to small entrepreneurs.

18- Start-Up India-

Rs.10,000 crore start-up funding pool. Reduction in patent reduction fees. Improved Bankruptancy Code, to ensure a 90 day exit window. No submission of Capital Gain Tax first 3yrs of operation. Create innovation hub. Promote India across the world as a start-up hub.

19- Stand Up India-

The scheme offers bank loans of between Rs.10 lakh and Rs.1crore for scheduled castes and scheduled tribes and women setting up new enterprises outside of the farm sector.

20- Make in India-

The scheme Make in India was launched on $25^{\text {th }}$ September 2014 with the objective of job creation and skill enhancement in 25 sectors of the economy and to transform India into a global design and manufacturing hub.

21- Google's vision ${ }^{12}$ -

Google India has set a target of creating an online presence for 20 million Small and Medium Enterprises (SMEs) in India on its various platforms by 2017. To achieve this target, the internet giant had launched a mobile application called "Google My Business".

\footnotetext{
${ }^{11}$ https://www.businesstoday.in/current/policy/six-major-govtinitiatives-to-improve-ease-of-doingbusiness/story/235194.html

12 http://www.forbesindia.com/article/special/google-indiaaims-to-bring-20-million-smes-online-by-2017/40347/1
}

\begin{tabular}{|l|c|}
\hline \multicolumn{2}{|c|}{ EASE OF DOING BUSINESS } \\
\hline $\mathbf{2 0 1 3}$ & 2017 \\
\hline $\mathbf{1 3 2}$ & 100 \\
\hline
\end{tabular}

India's ranking in ease of doing business in year 2013 and in year 2017, Report published by the World Bank.

\section{Conclusion and Suggestions-}

The analysis of the various problems and marketing activities of the Small business in India indicates that there is no single perfect plan for promotion Since MSME play a pivotal role in the economic and social development of the country, often acting as a foundation for growth entrepreneurship. The neglect of marketing will make the sector completely handicapped. MSMEs have been globally considered as an engine of economic growth and as key instruments for promoting equitable development. The marketing consultants as well as the Govt. must make effort to designing a viable plan for the development of the MSME sectors. The major advantage of the sector is its employment potential at low capital cost. The various alternative plan needs to be analysed to fin the a solution for the MSME sectors. In recent years, the MSME sector has consistently registered higher growth rate compared with the overall industrial sector. globalization can also act as a tool for development of the SMEs sector. SMEs engaged in manufacturing of engineering and automobile products have shown excellent growth over the years due to their expertise in supplying assemblies and sub-assemblies, components etc. What is needed is a rational policy which adequate support and protection to this sector enabling it to reach Indian markets. SMEs have many inherent advantages like exclusivity world, ability to produce small order quantities etc. In a globalised world, they can tap new markets, especially in the West where there is a big demand for handcrafted products. Information technology can be used as a tool to provide online information on indigenous products and producers, while Central legislations and patents can be used to prevent cheap imitations of designs and products by other countries.

To conclude, 2018 and coming years are going to be progressive changes in the Indian SME sector. Several policy interventions along with technology and innovation will continue to play a pivotal role in creating a business-friendly atmosphere for the SMEs. 